\title{
Flexible habitat selection and interactive habitat segregation in the marine congeners Idotea baltica and Idotea emarginata (Crustacea, Isopoda)
}

\author{
H.-D. Franke $\cdot$ L. Gutow $\cdot$ M. Janke
}

Received: 28 February 2006/ Accepted: 27 June 2006/ Published online: 27 July 2006

(C) Springer-Verlag 2006

\begin{abstract}
Habitat segregation among competing species is widespread yet very little is know how this is achieved in practice. In a case study, we examined short-term effects of conspecific and congeneric density on habitat selection in two competing marine isopod species, Idotea emarginata and Idotea baltica. Under semi-natural conditions in large outdoor cylindrical tanks ( $4 \mathrm{~m}$ high; volume $5.5 \mathrm{~m}^{3}$ ), animal groups of different size and composition had the choice between a set of relevant habitat samples (surface-floating seaweed, the water column, seaweed on the bottom). Habitat selection in both $I$. baltica and I. emarginata proved to be largely independent of conspecific density (level of intraspecific competition). In single-species treatments, both species showed a similar and stable pattern of distribution, with a clear preference for seaweed on the bottom. In mixed-species treatments (MST), however, the species were largely separated by habitat. While the distribution of I. emarginata was completely unaffected by the mere presence of interspecific competitors, habitat selection of I. baltica changed notably when I. emarginata was present. The habitat use patterns observed in MST conformed to those realized in geographical areas where the two species overlap in distribution: I. emarginata is dominant among decaying seaweed on the
\end{abstract}

Communicated by O. Kinne, Oldendorf/Luhe

H.-D. Franke $(\varangle) \cdot$ L. Gutow $\cdot$ M. Janke

Biologische Anstalt Helgoland, Foundation Alfred Wegener

Institute for Polar and Marine Research, Marine Station,

Box 180, 27483 Helgoland, Germany

e-mail: hfranke@awi-bremerhaven.de sea floor, and I. baltica is the dominant species among surface-floating seaweed. Our findings suggest that habitat segregation between the two species is essentially interactive, resulting from rapid decision-making of I. baltica with respect to habitat selection. The underlying mechanism is discussed. I. emarginata is highly superior to I. baltica in interference competition and rapidly eliminates the latter from one-habitat systems which do not allow I. baltica to escape from this interaction. In more natural, heterogeneous environments, however, I. baltica seems to be able to coexist with the superior competitor due to its broader habitat niche, flexibility in habitat selection, and a behavioural disposition to avoid normally preferred habitats when these are occupied by I. emarginata.

\section{Introduction}

Ecologists agree that a long-term coexistence of species within the same geographical range usually requires some degree of ecological segregation. Any difference in resource use patterns among species reduces interspecific competition, increases the probability of coexistence, and thus contributes to local species diversity. The most common form in which ecologically similar species partition available resources is by differences in habitat use (e.g. Schoener 1986): congeners are usually very similar in ecological requirements and thus have a high potential for interspecific competition; where congeneric species overlap on a coarse spatial scale (geographical range), they are usually found to be at least partially separated on a finer scale (habitat). 
However, whether the differences in niche dimensions among coexisting species have really been shaped by selection to reduce competition in natural communities is still a controversial topic in evolutionary biology (e.g. Arthur 1982; Schluter 2000). The present paper deals with the proximate rather than the ultimate factors of habitat segregation: very little is known about how habitat segregation between ecologically similar species is achieved in practice, i.e. which factors are actually causing and maintaining the observed differences in distribution. On principle, habitat segregation can result from differences in habitat selection, or else from processes, which take place after the animals have settled in particular habitats.

The marine isopods Idotea baltica and Idotea emarginata are mainly associated with uprooted, decaying brown algae and potentially compete for food and habitat. In geographical areas, however, where the species co-occur (British Isles, Helgoland), they are largely separated by habitat although some overlap may occur (Naylor 1955; Ingólfsson and Agnarsson 2003; and personal observations): I. baltica is the dominant isopod species among surface-floating seaweed (particularly the brown algae Ascophyllum nodosum and Fucus spp.); I. emarginata, in contrast, is typically found among decaying algal debris which, carried along by water currents, often forms large accumulations at calm locations on the sea floor. In geographical areas where I. emarginata does not occur (e.g. the Baltic Sea), its typical habitat appears to be occupied by I. baltica (Salemaa 1979). This suggests the latter species have a much broader potential habitat niche than is normally realized in the presence of its congener, I. emarginata.

In laboratory cultures, there is severe agonistic interference both within and between species, causing high mortality particularly on juveniles and individuals, which are about to moult (Franke and Janke 1998). Thus, experimental single-species populations of both I. baltica and I. emarginata rapidly attain an equilibrium size while all necessary resources are still available in excess. The aggressive interactions show two marked asymmetries: (1) Intraspecific interference (per individual) is much more severe in I. baltica than in I. emarginata. As a result, the latter species can build up much denser populations than the former. (2) Interspecific interference (per individual) of I. emarginata on $I$. baltica is much stronger than vice versa. As a consequence of these asymmetries, I. emarginata is highly dominant in competitive interactions, and eliminates $I$. baltica completely from mixed-species treatments (MST) within a relatively short period of time (Franke and Janke 1998).
These findings stimulated the present study on whether and how interactions between competing species (or simply the presence of potential competitors) may affect local habitat utilization by I. baltica and I. emarginata, and whether such interactions may be directly involved in habitat segregation of the species. Interactive habitat segregation between two potentially competing species implies that the distribution pattern of one or either species depends on the presence/absence of the respective other species. Examples of interactive habitat segregation refer particularly to congeneric species of insects (e.g. Howard and Harrison 1984; Suhling 1996), fish (e.g. Werner and Hall 1977; Larson 1980; Finger 1982; Bay et al. 2001; Bremset and Heggenes 2001; Sone et al. 2001), and terrestrial vertebrates (e.g. Douglass 1976; Hairston 1980; Bowers et al. 1987), but the exact mechanisms are poorly understood. Hardly anything is known about possible interactions leading to habitat segregation in marine invertebrates (review: Branch 1984). The present paper on two congeneric marine isopod species tries to reduce this gap.

All experiments were performed on a short-term basis so that any recorded differences in habitat use could be directly attributed to differences in habitat selection. In order to discriminate interspecific effects from mere crowding effects, it was necessary to study separately the effects of conspecifics and congeners on habitat selection by $I$. baltica and I. emarginata, respectively.

\section{Materials and methods}

Manipulative field studies are doubtless the most powerful and convincing approach in determining whether and how the presence of competitors affects habitat use patterns of members of an animal population. Due to practical problems, however, such studies are hardly feasible in small and highly mobile animals such as isopods of the genus Idotea. We therefore decided for what we consider the second-best approach to study this issue: definite groups of experimental animals were provided with a choice between a set of relevant habitat samples under semi-natural conditions in large mesocosms.

The experiments were conducted in 4-m-high outdoor cylindrical tanks containing $5.5 \mathrm{~m}^{3}$ of sea water (Fig. 1). Animal groups of different size (100, 200, 400, 800 , and 1,600 specimens) and composition (singlespecies groups of I. baltica and I. emarginata, respectively; mixed-species groups consisting of individuals of both species at equal densities) were released into the 


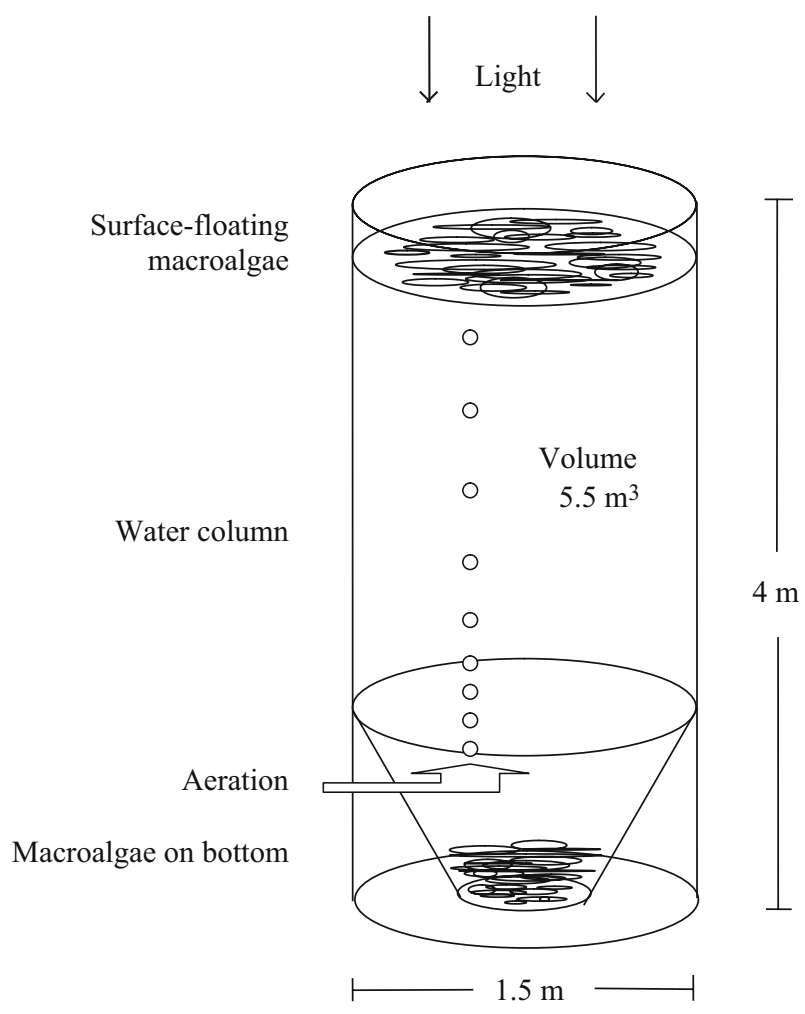

Fig. 1 Schematic diagram of outdoor tanks with arrangement of habitat samples as used in the habitat selection experiments

tanks where they were given the opportunity to distribute to three types of "habitat": (1) thalli of the macroalga $A$. nodosum (1.5 kg total wet weight) with intact pneumatocysts and, consequently, floating on the water surface; (2) the water column where the animals can stay only by more or less permanent swimming (clinging to the walls of the towers is nearly impossible as long as these are smooth and unfouled as it was the case during the experimental period); and (3) thalli of A. nodosum (1.5 kg total wet weight) settled down on the bottom (pneumatocysts opened or excised).

In a number of preliminary experiments, it had turned out that a largely stable pattern of distribution is achieved within less than 1 day, independent of the type of experiment. Extending the experimental period to 2,3 , and 4 days, respectively, never produced significantly different results. Furthermore, both males and females had proven to distribute across habitats independent of whether they were tested separately (unisexual groups) or jointly (bisexual groups). Based on these findings, all experiments were run for $22 \mathrm{~h}$ only, and although males and females were analysed separately, the experimental groups always consisted of both males and females (at equal densities). Size and composition of the studied animal groups (representing the different treatments) are given in Table 1. To avoid any interference with the diel cycle, the experiments were performed always over the same period of day, from 14.00 to $12.00 \mathrm{~h}$ the following day. At the end of each experiment, the animals associated with the three types of habitat were collected separately, classified by species and sex, and then counted. The recapture rate ranged from 94 to $100 \%$. After each trial, the tanks were drained and refilled with new sea water before the next trial was started.

For each habitat, the percentage of individuals found at the end of an experiment was analysed with respect to the factors species (two levels), sex (two levels), density (five levels), and single-/mixed-species treatment (two levels) by a four-way ANOVA after $\arcsin \sqrt{p}$-transformation of the proportions. Following the ANOVA, single pairs of means were tested for statistically significant differences by a Newman-Keuls post hoc test. As the results of the three ANOVAs were not independent of each other, the confidence interval was adjusted by a Bonferroni correction to $\alpha=0.05 / 3=0.017$. The density-dependence of distributional patterns was additionally subjected to regression analysis, and linear regression lines were compared to test for significant differences in slope according to Zar (1999).

In some cases (single-species-treatments and total density of 1,600 individuals per tank), the body length of representative subgroups of animals was measured (to the nearest $\mathrm{mm}$ ). The data were analysed by a oneway ANOVA, and means were compared pair-wise by a Newman-Keuls post hoc test.

The experiments were performed between early April and early May 1997, and were repeated in exactly the same way and during the same annual period in 2000. Three identical tanks were available for experimentation; the different treatments (with three simultaneous replicates each on the same day) were run on successive working days following the order given in Table 1 (1997) and in the reverse order (2000), respectively. The results of the 1997 and 2000 experiments did not differ statistically and were thus pooled so that each type of experiment is represented by a total of six replicates.

At the outset of the series of experiments, the water temperature within the tanks was about $7^{\circ} \mathrm{C}$ (both in 1997 and 2000), while by the end, it had increased to $10^{\circ} \mathrm{C}(1997)$ and $9^{\circ} \mathrm{C}(2000)$, respectively. A slight aeration from the bottom caused some mixing of the water column and ensured that temperature differences between bottom and surface water layers never exceeded $2^{\circ} \mathrm{C}$. The outdoor water tanks were exposed to the natural photoperiod; light could penetrate into the water column only from above (Fig. 1). 
Table 1 Experimental design: size and composition of animal groups studied; $E M$ Idotea emarginata, BA Idotea baltica, $T D$ total density (individuals per tower)
Each of the 15 types of experiment is represented by six replicates

\begin{tabular}{lccccr}
\hline Type of experiment & EM males & EM females & BA males & BA females & TD \\
\hline SST & 50 & & & & \\
1 & 100 & 100 & - & - & 100 \\
2 & 200 & 200 & - & - & 200 \\
3 & 400 & 400 & - & - & 400 \\
4 & 800 & 800 & - & - & 800 \\
5 & - & - & 50 & - & 1,600 \\
6 & - & - & 100 & 100 & 100 \\
7 & - & - & 200 & 200 & 200 \\
8 & - & - & 400 & 400 & 800 \\
9 & - & - & & 800 & 1,600 \\
10 & & & 25 & & \\
MST & 25 & 25 & 50 & 25 & 100 \\
11 & 50 & 50 & 100 & 50 & 200 \\
12 & 100 & 100 & 200 & 100 & 400 \\
13 & 200 & 200 & 400 & 200 & 200 \\
14 & 400 & 400 & 400 & 1,600 \\
15 & & & & & \\
\hline
\end{tabular}

The experimental animals (adult males ranging from 15 to $35 \mathrm{~mm}$ in body length; and adult females with 8-22 mm body length) were taken from long-established single-species laboratory mass cultures. These cultures run under nearly ambient temperature and light conditions, and originate from specimens collected off Helgoland (German Bight, North Sea).

\section{Results}

To simplify matters, we used the following contractions: $\%$-surface $=$ percentage of animals associated with the algal debris floating on the water surface; \%column $=$ percentage of animals swimming around in the water column; \%-bottom = percentage of animals associated with the algal debris on the bottom.

Figures 2 and 3 represent \%-surface, \%-column, and \%-bottom for each combination of species, sex, and treatment as a function of total density. Tables 2, 3 and 4 display the results of the four-way ANOVA for $\%$-surface, \%-column, and \%-bottom. With a single exception (\%-surface was independent of density), \%surface, \%-column and \%-bottom varied significantly with species, treatment (single- and mixed-species
Fig. 2 Habitat selection by Idotea emarginata $(E M)$ and Idotea baltica $(B A)$ in singlespecies treatments $(S S T) ; \%$ surface, \%-bottom, and \%column as a function of total density; $\bar{X} \pm \mathrm{SD}$ (six replicates each) with regression lines
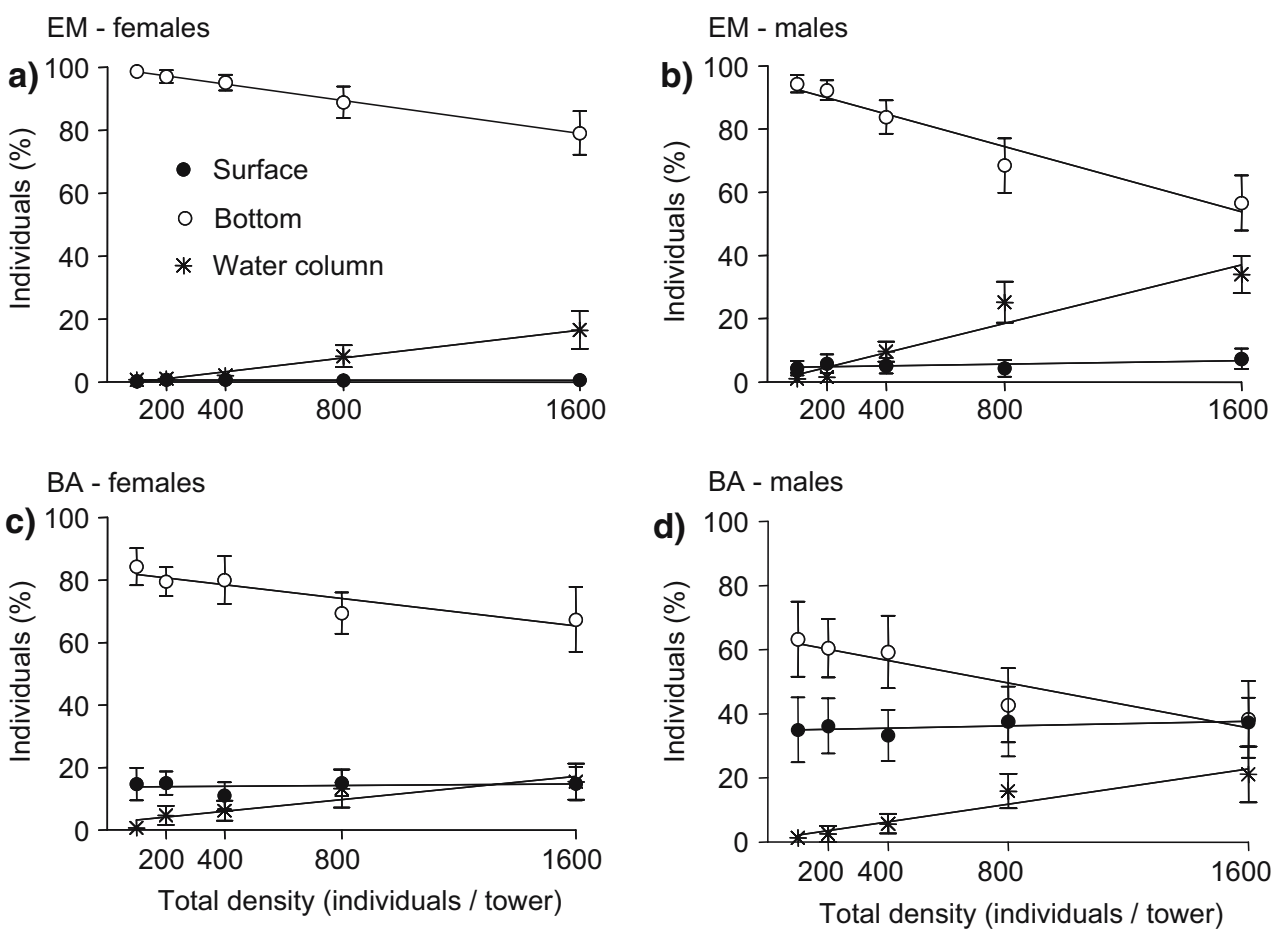
Fig. 3 Habitat selection by Idotea emarginata $(E M)$ and Idotea baltica $(B A)$ in mixedspecies treatments $(M S T)$; \%surface, \%-bottom, and \%column as a function of total density; $\bar{X} \pm$ SD (six replicates each) with regression lines
EM - females

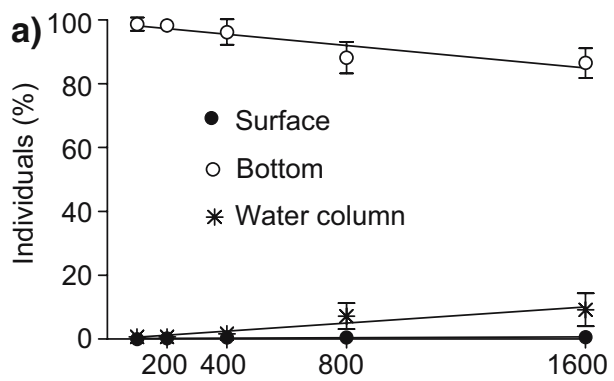

BA - females

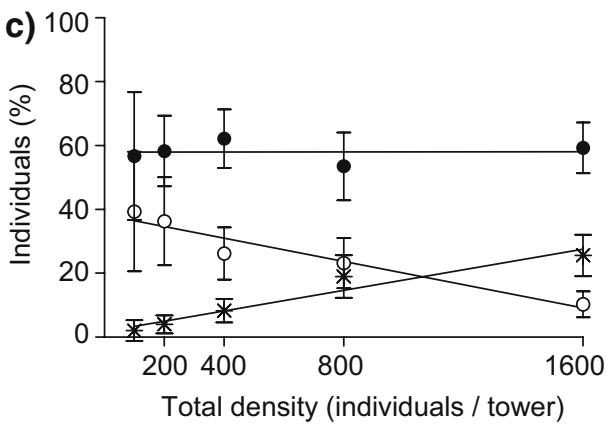

EM - males

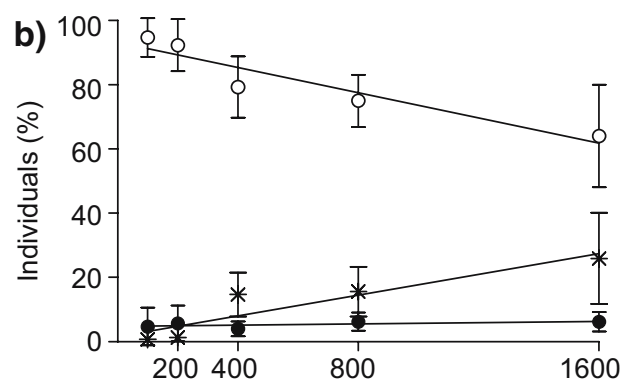

BA - males

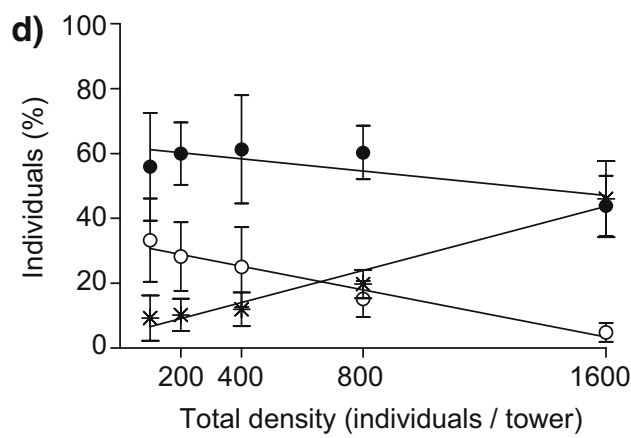

Table 2 Results of the fourway ANOVA for the percentage of individuals of Idotea emarginata and Idotea baltica associated with surface-floating seaweed (\%surface) after $22 \mathrm{~h}$ of habitat selection experiments
$N S$ non-significance $(P>0.017)$

\begin{tabular}{|c|c|c|c|c|c|}
\hline Source of variation & $d f$ & SS & MS & $F$ & $P$-value \\
\hline \multicolumn{6}{|l|}{ Main effects } \\
\hline Factor 1 (species) & 1 & 18.156 & 18.1566 & $2,016.443$ & $<0.001$ \\
\hline Factor 2 (treatment) & 1 & 1.543 & 1.543 & 171.343 & $<0.001$ \\
\hline Factor $3(\operatorname{sex})$ & 1 & 1.262 & 1.262 & 140.116 & $<0.001$ \\
\hline Factor 4 (density) & 4 & 0.032 & 0.008 & 0.828 & NS \\
\hline \multicolumn{6}{|l|}{ First-order interactions } \\
\hline Factors $1 \times 2$ & 1 & 2.077 & 2.077 & 230.624 & $<0.001$ \\
\hline Factors $1 \times 3$ & 1 & 0.025 & 0.025 & 2.746 & NS \\
\hline Factors $2 \times 3$ & 1 & 0.270 & 0.270 & 30.001 & $<0.001$ \\
\hline Factors $1 \times 4$ & 4 & 0.056 & 0.014 & 1.526 & NS \\
\hline Factors $2 \times 4$ & 4 & 0.028 & 0.007 & 0.766 & NS \\
\hline Factors $3 \times 4$ & 4 & 0.012 & 0.003 & 0.355 & NS \\
\hline \multicolumn{6}{|l|}{ Second-order interactions } \\
\hline Factors $1 \times 2 \times 3$ & 1 & 0.309 & 0.309 & 34.357 & $<0.001$ \\
\hline Factors $1 \times 2 \times 4$ & 4 & 0.060 & 0.015 & 1.616 & NS \\
\hline Factors $1 \times 3 \times 4$ & 4 & 0.040 & 0.010 & 1.146 & NS \\
\hline Factors $2 \times 3 \times 4$ & 4 & 0.048 & 0.012 & 1.299 & NS \\
\hline \multicolumn{6}{|l|}{ Third-order interactions } \\
\hline Factors $1 \times 2 \times 3 \times 4$ & 4 & 0.016 & 0.004 & 0.472 & NS \\
\hline Within subgroups (error) & 200 & 1.800 & 0.009 & & \\
\hline Total & 239 & 24.838 & 0.104 & & \\
\hline
\end{tabular}

treatment, respectively), sex, and density (main factors). The detailed results given below have all been verified by Newman-Keuls post hoc tests and regression analysis, respectively.

\section{Single-species treatments}

In single-species treatments (SST), the distribution of individuals across the different habitats and the 
Table 3 Results of the four-way ANOVA for the percentage of individuals of Idotea emarginata and Idotea baltica associated with seaweed on the bottom (\%-bottom) after $22 \mathrm{~h}$ of habitat selection experiments

$N S$ non-significance $(P>0.017)$

Table 4 Results of the four-way ANOVA for the percentage of individuals of Idotea emarginata and Idotea baltica swimming in the water column (\%-column) after $22 \mathrm{~h}$ of habitat selection experiments
$N S$ non-significance $(P>0.017)$

\begin{tabular}{|c|c|c|c|c|c|}
\hline Source of variation & $d f$ & SS & MS & $F$ & $P$-value \\
\hline \multicolumn{6}{|l|}{ Main effects } \\
\hline Factor 1 (species) & 1 & 16.536 & 16.536 & $1,427.802$ & $<0.001$ \\
\hline Factor 2 (treatment) & 1 & 2.423 & 2.423 & 209.235 & $<0.001$ \\
\hline Factor $3(\operatorname{sex})$ & 1 & 1.958 & 1.958 & 169.062 & $<0.001$ \\
\hline Factor 4 (density) & 4 & 4.144 & 1.036 & 89.489 & $<0.001$ \\
\hline \multicolumn{6}{|l|}{ First-order interactions } \\
\hline Factors $1 \times 2$ & 1 & 3.623 & 3.623 & 312.851 & $<0.001$ \\
\hline Factors $1 \times 3$ & 1 & 0.014 & 0.014 & 1.205 & NS \\
\hline Factors $2 \times 3$ & 1 & 0.113 & 0.113 & 9.766 & $<0.01$ \\
\hline Factors $1 \times 4$ & 4 & 0.148 & 0.037 & 3.208 & $<0.05$ \\
\hline Factors $2 \times 4$ & 4 & 0.044 & 0.011 & 0.921 & NS \\
\hline Factors $3 \times 4$ & 4 & 0.076 & 0.019 & 1.664 & NS \\
\hline \multicolumn{6}{|l|}{ Second-order interactions } \\
\hline Factors $1 \times 2 \times 3$ & 1 & 0.121 & 0.121 & 10.468 & $<0.01$ \\
\hline Factors $1 \times 2 \times 4$ & 4 & 0.080 & 0.020 & 1.747 & NS \\
\hline Factors $1 \times 3 \times 4$ & 4 & 0.040 & 0.010 & 0.863 & NS \\
\hline Factors $2 \times 3 \times 4$ & 4 & 0.012 & 0.003 & 0.266 & NS \\
\hline \multicolumn{6}{|l|}{ Third-order interactions } \\
\hline Factors $1 \times 2 \times 3 \times 4$ & 4 & 0.024 & 0.006 & 0.536 & NS \\
\hline Within subgroups (error) & 200 & 2.400 & 0.012 & & \\
\hline Total & 239 & 31.084 & 0.130 & & \\
\hline
\end{tabular}

\begin{tabular}{|c|c|c|c|c|c|}
\hline Source of variation & $d f$ & SS & MS & $F$ & $P$-value \\
\hline \multicolumn{6}{|l|}{ Main effects } \\
\hline Factor 1 (species) & 1 & 0.360 & 0.360 & 43.219 & $<0.001$ \\
\hline Factor 2 (treatment) & 1 & 0.060 & 0.060 & 7.177 & $<0.01$ \\
\hline Factor $3(\operatorname{sex})$ & 1 & 0.635 & 0.635 & 76.294 & $<0.001$ \\
\hline Factor 4 (density) & 4 & 5.904 & 1.467 & 177.217 & $<0.001$ \\
\hline \multicolumn{6}{|l|}{ First-order interactions } \\
\hline Factors $1 \times 2$ & 1 & 0.325 & 0.325 & 39.078 & $<0.001$ \\
\hline Factors $1 \times 3$ & 1 & 0.061 & 0.061 & 7.341 & $<0.01$ \\
\hline Factors $2 \times 3$ & 1 & 0.055 & 0.055 & 6.648 & $<0.05$ \\
\hline Factors $1 \times 4$ & 4 & 0.072 & 0.018 & 2.119 & NS \\
\hline Factors $2 \times 4$ & 4 & 0.024 & 0.006 & 0.710 & NS \\
\hline Factors $3 \times 4$ & 4 & 0.156 & 0.039 & 4.704 & $<0.01$ \\
\hline \multicolumn{6}{|l|}{ Second-order interactions } \\
\hline Factors $1 \times 2 \times 3$ & 1 & 0.056 & 0.056 & 6.703 & $<0.05$ \\
\hline Factors $1 \times 2 \times 4$ & 4 & 0.108 & 0.027 & 3.250 & $<0.05$ \\
\hline Factors $1 \times 3 \times 4$ & 4 & 0.200 & 0.050 & 6.032 & $<0.001$ \\
\hline Factors $2 \times 3 \times 4$ & 4 & 0.064 & 0.016 & 1.868 & NS \\
\hline \multicolumn{6}{|l|}{ Third-order interactions } \\
\hline Factors $1 \times 2 \times 3 \times 4$ & 4 & 0.036 & 0.009 & 1.030 & NS \\
\hline Within subgroups (error) & 200 & 1.600 & 0.008 & & \\
\hline Total & 239 & 7.504 & 0.031 & & \\
\hline
\end{tabular}

changes of these distributional patterns with increasing density were essentially similar in I. emarginata and I. baltica: individuals of both species, and both sexes, showed a clear preference for algal debris on the bottom. In detail, however, there were significant species- and sex-specific differences. Preference for the bottom was stronger in I. emarginata than in I. baltica, and in both species, it was stronger in females than in males. In all experimental groups, $\%$-surface was constant over the entire range of total densities (100 to 1,600 individuals per tower); it was lowest in I. emarginata females (about 1\%), significantly higher in I. emarginata males (about 5\%) and I. baltica females (about 15\%), and highest in I. baltica males (about 35\%). The \%-bottom always decreased with increasing total density, while \%-column increased correspondingly. This response was slightly (but significantly) more marked in males than 
in females; no difference was recorded between I. emarginata and I. baltica. The detailed results are as follows:

1. Idotea emarginata females (Fig. 2a) Out of the four species/sex-combinations, I. emarginata females showed the strongest preference for the bottom. At low densities (up to 400 individuals per tower), they were found nearly exclusively among algal debris on the bottom. At higher densities, \%-bottom dropped to about $80 \%$, while $\%$-column increased correspondingly. The $\%$-surface was negligible $(<1.2 \%)$ at all densities. Animals collected from the three habitats did not differ in body length (Fig. 4).

2. Idotea emarginata males (Fig. 2b) Males also strongly preferred staying on the bottom. In contrast to conspecific females, however, a significant portion (about $5 \%$ ) was always found associated with the water surface, independent of total density. As in females, \%bottom decreased and \%-column increased with increasing total density, but these changes were significantly more marked. Animals collected from the water column were significantly smaller than those from the bottom and the surface (Fig. 4).

3. Idotea baltica females (Fig. 2c) At all densities studied, female I. baltica clearly preferred the bottom. With increasing total density, \%-bottom slightly decreased from 85 to $70 \%$, and this was reflected in a corresponding increase in \%-column to about $15 \%$. In contrast to I. emarginata females, we always found a significant percentage (about 15\%) of animals associated with the water surface; this percentage did not change significantly with density. Animals collected from the three habitats did not differ in body length (Fig. 4).

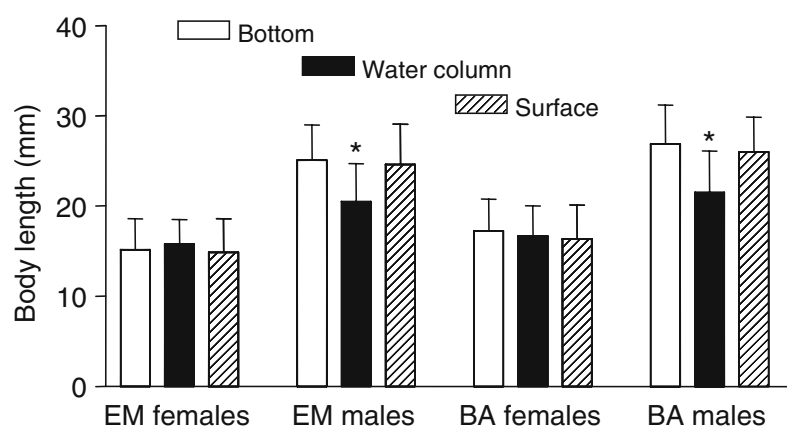

Fig. 4 Body length ( $\bar{X} \pm \mathrm{SD} ; N=150$ each) of males and females of Idotea emarginata $(E M)$ and Idotea baltica $(B A)$ collected from the surface, the water column, and the bottom (SST, total density: 1,600 individuals per tower). Significant differences (asterisk) were found only in males $(P<0.05)$ : in both species, males collected from the water column were significantly smaller than those from the bottom and the surface, respectively
4. Idotea baltica males (Fig. 2d) At low total densities, these animals also had a preference for the bottom, but this was clearly less pronounced than in the other three species/sex-combinations. The \%-surface was relatively high and constant $(35-40 \%)$ across all total densities. This was significantly more than in I. baltica females and in I. emarginata. With increasing total density, \%-bottom decreased from about 65 to about $35 \%$, and \%-column increased to more than $20 \%$. Thus it was only in I. baltica males, and at the highest total density studied (1,600 individuals per tower), that animals in SST did not show a clear distributional preference for the bottom. Animals collected from the water column were significantly smaller than those collected from the bottom and the surface (Fig. 4).

\section{Mixed-species-treatments}

There was a striking asymmetry between $I$. emarginata and I. baltica in how habitat selection was affected by the presence of the respective other species. Habitat selection in both male and female I. emarginata was completely unaffected by individuals of $I$. baltica. In contrast, individuals of $I$. baltica showed a striking change in habitat preference from "bottom" to "surface" when confronted with individuals of I. emarginata.

1. Idotea emarginata females (Fig. 3a) In almost every respect, habitat selection behaviour of $I$. emarginata females in mixed-species-treatments (MST) was not significantly different from that in SST. The only exception was: in MST, \%-column increased a little bit more strongly with increasing total density than in SST.

2. Idotea emarginata males (Fig. 3b) The distribution of I. emarginata males across habitats was independent of the presence/absence of I. baltica.

3. Idotea baltica females (Fig. 3c) In striking contrast to what was observed in SST, I. baltica females in MST showed a clear preference for the surface. Independent of total density, \%-surface was about $60 \%$. The \%bottom decreased significantly from about $40 \%$ at low total densities to about $30 \%$ at high densities while \%column increased correspondingly from 0 to about $30 \%$.

4. Idotea baltica males (Fig. 3d) The responses of I. baltica males to the presence of I. emarginata individuals were essentially similar to those of $I$. baltica females. There was usually a clear preference for "surface" instead of "bottom". The \%-surface was 
largely constant at about $60 \%$; the slight decrease at high densities was statistically not significant. The \%bottom decreased from about $35 \%$ at low densities to about $5 \%$ at high densities, while $\%$-column increased correspondingly.

\section{Discussion}

There is hardly anything which contributes more to the individual success of organisms than an "optimal" environment. Therefore, natural selection should have provided mobile animals with the ability to evaluate, relative to available alternatives, continuously and reliably their current living conditions, and to respond accordingly by staying or else leaving for places where their individual fitness may be increased. There can be little doubt that the differential use of available habitats by highly mobile species with efficient sensory and nervous systems is largely the result of an adaptive habitat selection strategy and is not merely due to differential survival. Optimal habitat choice in the wild is a highly complex performance: decisions on "staying or leaving" should not be based solely on the specific local conglomerate of physico-chemical conditions and the availability of necessary resources, but also on biological factors such as the levels of predation and competition which the animals probably would become exposed to in a particular place (e.g. Rosenzweig 1981; Křivan and Sirot 2002). Potential restrictions to individual fitness imposed by high local levels of predation and/or (intra- and interspecific) competition should be anticipated and considered when animals are choosing a place to live in.

Differential distribution across habitats

in single-species treatments

In SST, both I. emarginata and I. baltica (and both sexes) exhibited largely similar patterns of habitat use, with a strong preference for algal debris on the bottom. We can only speculate which factors render this habitat more attractive for the two species than the available alternatives. Idotea-species are not fitted for permanent swimming; their appearance in the water column is but a transitory event when animals are seeking new habitat patches. Association with surface-floating algal debris promotes passive dispersal (Thiel and Gutow 2005a, b), but in the long run, this life-style involves some serious disadvantages: surface-floating seaweeds represent unstable (ephemeral) and patchy microhabitats, which rapidly dwindle away. Their inhabitants have to meet high-energy costs to ensure, by swimming around in the water column, their arrival at new suitable habitats. However, the accumulation of surfacefloating debris at frontal regions may keep these costs within reasonable bounds. Furthermore, at the water surface, isopods are exposed to high levels of predation both by fish, which are attracted to floating objects (Wallerstein and Brusca 1982) and birds (Furness and Todd 1984). In contrast, accumulations of decaying algae on the sea floor are rather permanent habitats, characterized by relatively constant physical conditions, a reduced predation risk, and a continuous food supply through water currents.

Preference for bottom proved to be stronger in I. emarginata than in I. baltica, and in females than in males. This was a first indication of what became particularly evident in MST (see below): I. baltica (compared to I. emarginata) and males (compared to females) show a higher mobility and are more flexible in habitat selection. Sexual differences in activity and habitat selection are widespread among marine isopods and amphipods (e.g. Jormalainen and Tuomi 1989): while males are primarily selected for increased mating success (this includes increased mobility at the cost of increased predation risk), females are primarily selected for increased survival (reduced activity and staying in a more sheltered habitat especially when gravid) (Slatkin 1984).

In both Idotea species, habitat preference for algal debris on the bottom was largely stable over a wide range of densities, and thus levels of intraspecific competition, up to values far above those ever observed in nature (personal observations). Of particular interest is the finding that \%-surface was completely independent of density. The \%-surface did differ between species and sexes (about $1 \%$ in I. emarginata females, $5 \%$ in I. emarginata males, $15 \%$ in I. baltica females, and $35 \%$ in I. baltica males), and this may reflect species- and sex-specific heriditary differences in habitat selection; but for each combination of species and sex, \%-surface was constant. Actually, we do not know what (if anything) distinguishes individuals which selected for the bottom from those which were found on the water surface. Their different behaviour might be related to changes in individual needs over the moult or/and the reproductive cycle. The average body length of these two groups of animals, however, was not significantly different.

Responses to increasing conspecific density, however, were evident in a gradual decrease of \%-bottom and a corresponding increase in \%-column. These changes were more pronounced in males than in females. When a habitat becomes crowded, the individ- 
ual fitness of its inhabitants (and thus the habitat's attractiveness) decreases. It is particularly less-fit individuals which should profit from leaving a crowded habitat and trying to arrive in habitats with lower levels of intraspecific competition. The competitive ability of males of the genus Idotea is strongly dependent on body size: the body length of adult males ranges between 15 and $35 \mathrm{~mm}$ (adult females: 8-23 $\mathrm{mm}$ ), and in aggressive encounters (interference competition), smaller males are inferior to larger ones; furthermore, in an overcrowded habitat, smaller males have hardly any chance to reproduce because they usually become displaced from females in precopula by larger males (Jormalainen et al. 1992; Franke and Janke 1998; and personal unpublished observations). Our findings confirm the expectation that competitively inferior rather than superior males should leave a crowded habitat: males collected from the water column were significantly smaller than those collected from the bottom.

Considering the fact that the total density in our experiments covered an extremely wide range (factor 16: from 100 to 1,600 individuals per tower), the observed responses to increasing conspecific density were surprisingly weak. Furthermore, habitat choice in I. baltica did not prove to be more sensitive in this respect than that in I. emarginata, although the per capita intraspecific competition in I. baltica is about four times higher than in I. emarginata (Franke and Janke 1998). This may be taken as an indication that levels of intraspecific competition at which individuals would profit from shifting in habitat are normally not achieved, i.e. that populations of both species in the field are usually limited by factors such as predation rather than by intraspecific competition (resource competition or agonistic interference). Under these circumstances, natural selection could not act in favour of individuals, which show a marked response to intraspecific competitors when selecting their habitat.

\section{Interactive habitat segregation}

If in MST both Idotea species retained the habitat preferences exhibited in SST, the two species would largely overlap in habitat use. This, however, was not observed. In MST, I. emarginata and I. baltica were found largely separated by habitat, and their habitat use patterns correlated with the natural distributions in geographical areas where the two species co-occur: I. emarginata is the dominant species among decaying seaweed on the sea floor while I. baltica dominates among surface-floating seaweed. From these findings, we conclude that habitat segregation between I. emarginata and $I$. baltica in the experimental treatments (and probably also in the field) is essentially interactive. However, there was an extreme asymmetry in the species' responses to one another. Habitat segregation resulted from a striking shift in habitat selection from "bottom" to "surface" which I. baltica underwent when its normally preferred habitat ("bottom") was occupied by I. emarginata. In contrast, the distribution of I. emarginata across habitats proved to be virtually independent of the presence/absence of its congener I. baltica.

To explain these findings, we have to refer to what is known about competitive interactions between I. emarginata and I. baltica (Franke and Janke 1998). The species compete severely by direct aggressive interference. We therefore expect that individual fitness in a habitat strongly depends on interspecific density and that animals may shift in resource (e.g. habitat) use patterns in apparent response to one another. Competitive interactions between species are usually asymmetric (Lawton and Hassell 1981; Connell 1983; Schoener 1983), and the inferior species can be expected to shift more in response to the superior one than vice versa. In extreme cases, i.e. if one species is highly dominant in competition, the superior species might remain unaffected by the presence of the inferior species, while the latter would undergo a marked change in resource use when confronted with the former.

This scenario exactly conforms to the situation of I. emarginata and I. baltica. The former is highly dominant in interference competition. In a one-habitat environment where animals cannot escape mutual aggressive attacks, I. baltica becomes rapidly eliminated by I. emarginata (Franke and Janke 1998). For I. emarginata, there is thus no need to adjust its habitat selection behaviour according to the absence/presence of I. baltica. For I. baltica, however, the situation is completely different; this species has no realized niche in a habitat, which is occupied by I. emarginata. I. baltica profits from accumulations of decaying seaweed on the sea floor as long as I. emarginata is absent from this suitable habitat, but avoids this habitat when it is occupied by I. emarginata.

The ability of $I$. baltica to modify habitat selection according to the presence/absence of I. emarginata is an important adaptation which reduces the two species' overlap in habitat, and probably allows for their coexistence in a heterogeneous environment.

In a theoretical study, Krrivan and Sirot (2002) have modelled adaptive habitat selection strategies of two competing species in an environment consisting of two habitats of different quality. For the particular case which corresponds to the situation in I. emarginata and I. baltica (i.e. both species prefer the same, more 
profitable habitat when alone; interspecific competition is very strong compared to intraspecific competition, and is asymmetric), the model predicts complete habitat segregation and coexistence of the species at the scale of the whole environment, with the dominant species staying in the more profitable habitat and the subordinate species being restricted to the less preferred (and less profitable) habitat.

At first glance, surface-floating seaweed might be regarded a suboptimal habitat, underused by I. emarginata and thus presenting a refuge to I. baltica where this species can escape detrimental interspecific effects when its normally preferred habitat is occupied by the dominant I. emarginata. However, this view does not adequately realize the significance of surface-floating seaweed as a habitat for I. baltica. Floating objects such as uprooted macroalgae represent effective vehicles for a passive long-distance dispersal and colonization of far-away new habitats. This is particularly important to species such as isopods, which lack long-lived pelagic larvae. Even in the SST, there was always a certain percentage of I. baltica (but not of I. emarginata) which preferred settling among surface-floating seaweed. Apparently, I. baltica is adapted to use a broader spectrum of habitats than I. emarginata. A more generalist habitat use, the observed flexibility in habitat choice, and the extensive use of surface-floating seaweed for passive dispersal may be the main factors responsible for the greater evolutionary success (distribution and abundance) of I. baltica compared to I. emarginata. I. baltica is a common species in coastal waters with a nearly cosmopolitan distribution (Naylor 1972) while I. emarginata is restricted to the European Atlantic coast from Norway to Spain. I. emarginata has a more specialist habitat use, is rather inflexible in habitat choice, and has a much lower potential of dispersal. Although able to exclude I. baltica from preferred habitats where the two species overlap in distribution, on a long-term basis, I. emarginata probably will reveal as the "weaker" species running a much higher risk of extinction than its congener I. baltica.

The mechanism of interactive habitat segregation

In cases of interactive habitat segregation between species, which compete for resources, it is often not clear whether the animals respond to the mere presence of each other or to competitor-induced changes in local ecological conditions (e.g. in the availability of commonly used resources). In our experiments on Idotea species (where both intra- and interspecific competition is exclusively by direct interference), the differences in distributional patterns recorded in relation to overall density and absence/presence of the congeneric species, respectively, became evident within only a few hours and remained stable for at least 4 days (observations over longer periods of time have not been carried out yet). This implies that such differences cannot be attributed to detrimental effects of competition on life cycle parameters but reflect rapid behavioural changes in habitat selection. If alternative habitats are available, I. baltica does not passively await its inevitable elimination from the preferred habitat by I. emarginata. I. baltica is capable of realizing the presence of I. emarginata; the species seems to anticipate an imminent drastic decrease of its fitness by co-occurring I. emarginata, and adjusts accordingly by modifying its habitat selection behaviour.

What cue causes I. baltica to switch in habitat choice when I. emarginata is present? The relevant information might be achieved in different ways: (1) One possibility would be: by vision. However, this seems little probable considering the two species' quite similar morphology and poorly developed visual system. (2) Frequent direct behavioural interactions, e.g. aggressive attacks of I. emarginata on I. baltica might make I. baltica shift in habitat. Aggressive interactions among species are an important determinant of habitat partitioning, e.g. in coral reef fish (Ebersole 1995; Robertson 1996; Bay et al. 2001). This mechanism might well account for rapid behavioural responses such as those described in the present paper. (3) Ultimately, chemicals released from I. emarginata into the medium (or deposited on the substratum) might act on I. baltica as a deterrent or repellent. The use of chemical cues in choosing optimal habitats is particularly evident in larval settlement and metamorphosis of sessile organisms; chemicals acting as inducers (or inhibitors) of this process can originate from various sources including conspecific and congeneric individuals (Qian 1999; Steinberg and de Nys 2002; Fusetani 2004). Very little is known, however, about the importance of chemical information from competitors for habitat selection in mobile species. There is some evidence in the water flea Daphnia that chemicals are involved in habitat segregation between competing species. Infochemicals released from (intra- und interspecific) competitors affected a number of life history parameters of Daphnia pulex and Daphnia cucullata (Matveev 1993; Boersma et al. 1999; Lürling et al. 2003), and Daphnia magna was found to avoid media, which had been inhabited by $D$. pulex (Roozen and Lürling 2001).

Although preliminary experiments designed to test for a water-borne (or substrate-sticking) repellent released by I. emarginata did not yet yield conclusive 
results, Idotea species have revealed as excellent experimental systems to elucidate the mechanisms of habitat segregation. The present paper is the first on marine invertebrates, which clearly shows that habitat segregation between two ecologically similar species can result from a rapid decision-making of individuals able to anticipate and consider potential local levels of interference competition when selecting a habitat.

\section{References}

Arthur WA (1982) Evolutionary consequences of interspecific competition. Adv Ecol Res 12:127-187

Boersma M, DeMeester L, Spaak P (1999) Environmental stress and local adaptation in Daphnia magna. Limnol Oceanogr 44:393-412

Bay LK, Jones GP, McCormick MI (2001) Habitat selection and aggression as determinants of spatial segregation among damselfish on a coral reef. Coral Reefs 20:289-298

Bowers MA, Thompson DB, Brown JH (1987) Spatial organization of a desert rodentcommunity: food addition and species removal. Oecologia (Berlin) 72:77-82

Branch GM (1984) Competition between marine organisms: ecological and evolutionary implications. Oceanogr Mar Biol 22:429-593

Bremset G, Heggenes J (2001) Competitive interactions in young Atlantic salmon (Salmo salar L.) and brown trout (Salmo trutta L, in lotic environments. Nord J Freshw Res 75:127-142

Connell JH (1983) On the prevalence and relative importance of interspecific competition: evidence from field experiments. Am Nat 122:661-696

Douglass RJ (1976) Spatial interactions and microhabitat selections of two locally sympatric voles, Microtus montanus and Microtus pennsylvanicus. Ecology 57:346-352

Ebersole JP (1995) Niche separation of two damselfish species by aggression and differential microhabitat utilization. Ecology 66:14-20

Finger TR (1982) Interactive segregation among three species of sculpins (Cottus). Copeia 3:680-694

Franke H-D, Janke M (1998) Mechanisms and consequences of intra- and interspecificinterference competition in Idotea baltica (Pallas) and Idotea emarginata (Fabricius) (Crustacea: Isopoda): a laboratory study of possible proximate causes of habitatsegregation. J Exp Mar Biol Ecol 227:1-21

Fusetani N (2004) Biofouling and antifouling. Nat Prod Rep 21:94-104

Furness RW, Todd CM (1984) Diets and feeding of fulmars Fulmaris glacialis during the breeding season: a comparison between St Kilda and Shetland colonies. Ibis 126:379-387

Hairston NG (1980) The experimental test of an analysis of field distributions: competition in terrestrial salamanders. Ecology 61:817-826

Howard D, Harrison R (1984) Habitat segregation in ground crickets: the role of interspecific competition and habitat selection. Ecology 65:69-76

Ingólfsson A, Agnarsson I (2003) Amphipods and isopods in the rocky intertidal: dispersal and movements during high tide. Mar Biol 143:859-866

Jormalainen V, Tuomi J (1989) Sexual differences in habitat selection and activity of the colour polymorphic isopod Idotea baltica. Anim Behav 38:576-585
Jormalainen V, Tuomi J, Merilaita S (1992) Mate choice for male and female size in aquatic isopod Idotea balthica. Ann Zool Fenn 29:161-167

Křivan V, Sirot E (2002) Habitat selection by two competing species in a two-habitatenvironment. Am Nat 160:214-234

Larson RJ (1980) Competition, habitat selection, and the bathymetric segregation of two rockfish (Sebastes) species. Ecol Monogr 50:221-239

Lawton JM, Hassell MP (1981) Asymmetrical competition in insects. Nature 289:793-795

Lürling M, Roozen F, van Donk E, Goser B (2003) Response of Daphnia to substances released from crowded congeners and conspecifics. J Plankton Res 25:967-978

Matveev V (1993) An investigation of allelopathic effects of Daphnia. Freshw Biol 29:99-105

Naylor E (1955) The ecological distribution of British species of Idotea (Isopoda). J Anim Ecol 24:270-281

Naylor E (1972) British marine isopods. Synopses of the British Fauna (New Series) No. 3. Academic Press, London

Qian PY (1999) Larval settlement of polychaetes. Hydrobiologia 402:239-253

Robertson DR (1996) Interspecific competition controls abundance and habitat use of territorial Caribbean damselfishes. Ecology 77:885-899

Roozen F, Lürling M (2001) Behavioural response of Daphnia to olfactory cues from food, competitors and predators. J Plankton Res 23:797-808

Rosenzweig ML (1981) A theory of habitat selection. Ecology 62:327-335

Salemaa H (1979) Ecology of Idotea spp. (Isopoda) in the northern Baltic. Ophelia 18:133-150

Schluter D (2000) Ecological character displacement in adaptive radiation. Am Nat 156:S4-S16

Schoener TW (1983) Field experiments on interspecific competition. Am Nat 122:240-285

Schoener TW (1986) Resource partitioning. In: Kikkawa J, Anderson DJ (eds) Community ecology: pattern and process. Blackwell, Oxford, pp 91-126

Slatkin M (1984) Ecological causes of sexual dimorphism. Evolution 38:622-630

Sone S, Inoue M, Yanagisawa Y (2001) Habitat use and diet of two stream gobies of the genus Rhinogobius in south-western Shikoku, Japan. Ecol Res 16:205-219

Steinberg PD, de Nys R (2002) Chemical mediation of colonization of seaweed surfaces. J Phycol 38:621-629

Suhling F (1996) Interspecific competition and habitat selection by the riverine dragonfly Onychogomphus uncatus. Freshw Biol 35:209-217

Thiel M, Gutow L (2005a) The ecology of rafting in the marine environment. I. The floating substrata. Oceanogr Mar Biol 42:181-263

Thiel M, Gutow L (2005b) The ecology of rafting in the marine environment. II. The rafting organisms and community. Oceanogr Mar Biol 43:279-418

Wallerstein BR, Brusca RC (1982) Fish predation: a preliminary study of its role in the zoogeography and evolution of shallow water idoteid isopods (Crustacea: Isopoda: Idoteidae). J Biogeogr 9:135-150

Werner EE, Hall DJ (1977) Competition and habitat shift in two sunfish (Centrarchidae). Ecology 60:256-264

Zar JH (1999) Biostatistical analysis, 4th edn. Prentice-Hall, Upper Saddle River, NJ 